\title{
Teaching Students, Not Texts
}

\author{
Scot Douglass \\ Herbst Humanities Program, University of Colorado--Boulder
}

\section{Context}

"What works and doesn't work?" in the integration of an engineering curriculum with the humanities has been a question we've been asking since the fall of 1989 when the College of Engineering and Applied Science at the University of Colorado, Boulder, began a new and innovative program of Humanities for Engineers. This program was made possible by the generous gift of an alumnus, Clarence Herbst, Jr. (Ch. E., '50). Now in its eighth year, the program, with a faculty of four, has become an established part of the college's culture. Offered as an upper-division elective, our main, two semester seminar interacts with approximately a fifth of the juniors and seniors amongst the college's twenty-four hundred under-graduate students. Our experience, of course, has been a mixed one and we have made many methodological and curricular adjustments and changes. Currently we enjoy a popular standing amongst students-there is a waiting list to get in the program--and a certain sense of satisfaction as teachers.

\section{Framing the Question}

The past three years of the Herbst program has seen almost a complete turn over in faculty--an extended leave, law school, a new direction, all concurrent with program expansion. Although the director and co-founder, Athanasios Moulakis, has remained, none of the other current teachers were here four years ago. During the transition years, the suggestions of new faculty for the common curriculum were regularly greeted with a variation of the following: "Oh, we tried that; it didn't work." As more new blood infused more "old" ideas, a new question surfaced: "What do we mean 'it didn't work?"' Had texts and methods been discarded in the early years because experience had yet to inform expectations? Did allegiance to certain methods preclude certain texts which otherwise, using different methods, would "work?"

Before we could answer the question, "Did it work?" other questions laid claim to a prior necessity. Foundational issues and concerns resurfaced and, on a retreat, the new faculty began its own pedagogical discourse informed by, but separate from the one it had inherited.

A preliminary question which probes one's central conception of what it means to teach is "Has the teacher taught if the student hasn't learned?" Attempts to arrive at an answer have proven, at least for me and colleagues of mine, productively inconclusive.

The simple answer, "No, if the student hasn't learned, I haven't taught," has a certain chivalrous ring, but does not satisfy for a number of reasons. To always be true, it must posit a universal, ideal student whose desire to learn, even if buried but accessible, is so great that only bad teaching can stand in its way. The voice of Epictetus cries over the centuries, "You have set yourself up for unhappiness if your success as a teacher depends upon factors outside of your control." If a miserable semester follows a wonderful semester, is it fair to say, "I did everything 
the same, but one semester I taught and the other semester I didn't"? Or within the same class, "I taught seventeen students and did not teach twelve"? Or contra Epictetus, can an answer of "no" attempt to recuperate a Stoic position on a psychological level by saying something of the following: "Everything does depend upon me--I am in control--and if I try just a little harder and apply just the right method, if I re-evaluate and get enough feedback from students, I really can guarantee that students will learn!" Except for the neuroses that such a position would produce, there is something attractive in believing one can discover "the" method that guarantees success.

On the other hand, to say "Yes" or even a more cautious "Maybe" does not suffice either. Is it always the student's fault if she does not learn? Can a teacher's heart say "I've taught something that no one learned"? Does the very definition of teaching demand learning? If not, could a teacher teach if there were no students? Of course, we have all left classes wondering if we have just attempted to do that very thing; but when we have, despite our frustration with the "not really there" students, do we feel or think we have taught?

The question--“Has the teacher taught if the student hasn't learned?"--demands its own interrogation. What does it mean that a student has learned? This is an especially complex question when teaching humanities to engineers. One could argue that an English major has learned if they know all the plot lines, characters, interpretive possibilities, historical allusions and dates of composition of all the plays by Shakespeare. These facts could be seen as equally fundamental to his career trajectory as learning the basic equations of algebra or calculus is to the engineer. Perhaps, but our desires as liberal educators of engineers transcend the transfer of humanistic content. Humanities in the university program of an engineer has to engage the student, somehow, with the question: "What does it mean to be a human?" To learn, in this sense, cannot be measured in terms of knowledge and right answers.

\section{Teaching Students, not Texts: The Classroom as Wrestling Mat}

Which brings us to the title of this paper, "Teaching Students, not Texts." In one sense, this phrase reveals a method. In another sense, it speaks more of a goal. In the Herbst Program of Humanities for Engineers, it is both. As a method, it informs how we conduct seminars, organize the learning environment, and expand our requirements outside of the classroom. As a goal, it enlivens our passion, sharpens our focus, and pitches our expectations.

Ironically, we have concluded that the best method to "teach students, not texts," is almost completely text-based. The text, though, does not embody what they learn; but rather is the arena in which they learn. The text both circumscribes and colors the space within which students interact. Our seminars are like a wrestling match. One student gets on the mat to grapple with Dostoevsky, only to find himself wrestling with another student who has jumped into the fray because he disagrees with how his fellow student is wrestling. Then perhaps another student, in tag-team fashion, adds her strength to the first student's. In the end, an entire class can be productively spent, students wrestling with one another--even though Dostoevsky's full wrestling weight is never unleashed by the superior reading of the teacher. As a result, we regularly "sacrifice" texts on the altar of a student's intellectual formation. How can we say, though, a student has learned if we know they walk away misunderstanding Dostoevsky?

Because the students have learned to wrestle better. They have engaged a complex question and 
have discovered the limitations of inadequate preparation. They have learned the power of using the text in the formulation of their understanding. They have grown in their ability to discern fruitful directions of inquiry from rabbit trails. They have been surprised by the limitations of their own self-referentiality. They have worked together with peers, their future peers, to refine their understanding of what it means to be human. They have gotten upon the mat of humanism with the expectation of gaining from the experience.

Our students engage each other and the texts much more productively, enthusiastically and efficiently by the end of two semesters of wrestling. Texts they productively misread the first week of class, they later integrate back into the discussion with refinement. We work hard to construct an environment which entices their engagement, does not stifle their initial clumsiness, subverts their expectations of the role of teacher and the role of student, and honors the honest pursuit of knowledge.

The text is essential to our method. It is the one story that is common to all the stories represented in the classroom. It provides the quality of the content and keeps all the wrestlers on the same mat. We strictly enforce the general rule: you cannot bring in an outside source (another text, a scene from a movie or a television show, a lengthy personal story, etc.) if the majority of the class is unfamiliar with it. The texts are granted a privileged status as the central reference point for all class discussions. Students, following the example of their teachers, learn to ask each other, "That sounds good to me, but can you show me how you got that from the text?" or "Where is that in the text?" or "How does that fit with what Socrates says here?" in response to a statement like "Well, I think Socrates is just saying that everyone needs to stand up for what they believe."

We desire to avoid the two extremes of "this is what you should think" and "whatever you think is wonderful"-- the sterility of memorizing and regurgitating the 'right answers' and the chaotic, self-referential blindness of speaking from a belief in the inherent truthfulness and equality of personal opinion. The balance we seek is having students actively and productively listen to well-developed voices, first through their own reading and then via classroom dialectic; and, then, we have them clarify/justify their understandings of the relevance/non-relevance of this voice to their own lives. We respect their abilities to engage an issue enough to challenge their initial thinking, invite them to think again in light of this or that and, generally, ask for more from them.

\section{Concretizing our Principles}

I would like to be more specific, more concrete, in how these general principles are enacted. To create an environment where students are willing to wrestle with each other over substantive questions, we do the following:

Class Size: We have experimented both intentionally and unintentionally, as a result of variable enrollment, with different class sizes. We have had as few as seven students in a particular seminar and as many as eighteen. There seem to be certain upper and lower thresholds of how crowded a class feels between which a reticent or shy student feels more uncomfortable in not participating than in participating. Given the physical 
dimensions of our specific seminar room, if there are more than fourteen students, it is very easy for an individual to feel justified in not participating. When a class feels too crowded, students privately argue that participation would mean forcing themselves into the conversation in such a way that would require rudeness and heroic boldness. In classes smaller than nine, they feel their participation is too highlighted. They relate that they feel too isolated from the rest of the class. In speaking, a student draws too much attention to himself. There is a balance in setting up a situation in which a student feels enough anonymity to risk participation and not enough anonymity to think they can hide. When we have had smaller classes, there has been a noted improvement in the quality of conversation when we have moved to a smaller classroom with a smaller table.

Number of Moderators: In the first semester of our two semester seminar, we have two moderators (instructors) in each class. We do this for a number of reasons. First, it undermines the students' expectations of the student-teacher relationship. They cannot focus their attention, even their physical gaze, on one source of information--one locus of "correct answers." Seated at a round table with a moderator on either side of the room, a student cannot engage both moderators without at least looking at the majority of their classmates. Secondly, the dual moderator models the idea of community learning. Thirdly, the two moderators can demonstrate participation skills by asking clarifying questions of each other, by referring a student back to a question or comment made by the other moderator, by taking a comment by the other moderator and pointing out a supporting text or adding an additional thought. The moderators are able to embody with each other how students should interact with other students.

Establishing Participation Expectations: For the engineering student, what we offer is different enough from their normal classroom experience, we have the freedom to establish our own set of expectations. In the first class, we explain that the goal of our seminars is not merely the gaining of humanistic content, but learning to actively engage themselves and their peers about what it means to be human. We underscore the differences between their study of the humanities and that of their Arts and Science colleagues. Namely, that since they know they will graduate and get jobs in the engineering field, the main reason for their studying works of literature and philosophy is the relevance of these works to their lives (as opposed to learning the humanities to later teach them). We structurally support this by basing a full third of their grade on the quality of their participation and having no content quizzes or exams. We attempt to clarify from the beginning that good participation is not a function of the quantity of comments made in class, but is based on a number of fairly well-defined criteria. In respect to participation, each student is evaluated according to the following six categories.

1) Quality of listening as demonstrated in the coherency of his comments with those of others.

2) Commitment to group learning as seen in her respect for the ideas of others, a certain civility in the treatment of others, an active commitment to including the entire class, etc. 
3) Pre-class preparation as evidenced in an ability to interact with the main substance of that day's text, to find relevant passages and be able to place those passages within their overall context.

4) Self-challenge as seen in the willingness to suspend personal judgment until a more accurate understanding of the text is obtained.

5) Personal presentation as observed in how they sit, whether or not they talk or make noises while others are speaking, whether or not they distract the class via fidgeting, twirling their pen, etc.

6) The amount of their participation measured by the amount or volume of quality contributions.

These categories are somewhat subjective; but we have found that when moderators coteaching a class independently calculate grades for individual students, there is agreement in the vast majority of cases. This is another advantage of having two teachers in each class--the ability to compare notes and minimize the impact of a teacher's particular disliking or liking of a student.

Enticing Engagement: As moderators, we attempt to structure the classroom experience in such a way that it helps students "find their voice." At the beginning of the semester, this can take the form of requiring each student to speak briefly about something that is relatively safe. "What specific passage from Frederick Douglass did you find especially striking? Read it out loud and tell us why?" "What is one question you have about a particular part that you found confusing or unclear?" Requiring students to all say something, anything, seems to make it easier for them to volunteer their own comments later. As the semester progresses, we attempt to structure participation less and ask for more initiative from the students. As moderators, we are committed to outlasting their reticence, of not rescuing them out of their silence and waiting for them to get frustrated enough with the boredom of the moment to do something.

Attention to Dynamics: The moderators occasionally stop class to make observations about the dynamics of the discussion. "How many of you feel left out of this conversation?" when the class discussion has turned into a repeated back and forth between two students. "How many of you are bored with this topic and want to move onto something else?" "How many of you think we're repeating ourselves and are stuck?" and "Can anyone identify where we're stuck and ask a question that will help get us unstuck?" "How do any of the last four comments relate to each other" or more specifically, "Wait a second, how did what you just said relate to the question that John just asked?" We also require two individual conferences per semester whose main focus is how each student is doing in respect to class participation.

Moderator Restraint: The moderators do not end class by saying something like, "This was a good discussion, but let me tell you what the text really means." Early in the first semester, students will frequently turn to the teachers and ask for a definitive reading. They will proclaim their frustration at the end of the class because we have not come to any real conclusion and haven't answered the main questions we were asking. At such 
times, the moderators ask the class to remember such feelings for the next class and focus on being more efficient. We also make ourselves available in office hours for more interaction about the text as well as encouraging the students to continue the discussion with each other outside of the classroom. When a discussion of a secondary point is struggling, we will occasionally ask the students, "Would you rather keep searching for an answer to this question or get an answer from us (if we have one) and use that to move onto other more central questions?"

Text Orientation: As stated above, we are very "text-o-centric." We emphasize close reading and use the "text" (including operas, movies, art and music as types of text) to create a learning space. In this space, how the student learns and interacts with the text is as important as how well they understand the text. In this sense, we are very methods oriented. The text is granted authority, not in respect to arbitrating truth and reality, but in presenting its own meaning. The goal of each class is to understand the text in own terms and then question to what degree it accurately describes or informs life.

Short Term vs. Long Term: We understand that our program may constitute the last formal humanities learning environment in which these future engineers participate. Because of this, we attempt to train them in reading skills which will allow them to engage texts in the future with a realistic expectation of gaining something from them. This is another reason why we exercise moderator restraint. They will not have access to "authoritative readers/teachers" in the future. We hope and suggest, though, that they will be able to duplicate a Herbst style reading group with future colleagues and friends. I have taught literary thinking groups at the Hewlett-Packard facilities in Fort Collins and Loveland.

\section{Relevant Observations of the Engineering Student}

As stated above, we have designed our program with the engineering student in mind. The following is a list of what we consider to be key observations regarding the students we serve. It goes without saying that this list is very general and does not apply to every engineering student.

- They are very diligent, responsible and accustomed to working very hard. They even pride themselves on the amount of work they do relative to students in other colleges in the university. Application: We give them, on average, one homework assignment per week which focuses upon some reading skill as well as prepares them for better class participation. Typical literary "homework sets" this past semester were finding ten examples of irony in Oedipus Rex and briefly explain why/how each is ironic, rewriting Book 1.1 of Aristotle's Nicomachean Ethics in their own words and using their own examples, as well as exploring interpretive problems such as what does the Grand Inquisitor mean when he says, "But I awakened and would not serve madness."

- On the whole, they are very intelligent.

- They are very practical in the way they think and the way they learn. They are used to doing homework sets and learning through repetitive application. Unlike the "hard 
sciences," they seek answers that work given a variety of competing variables/limitations. Application: Similar to the principles behind the above comments regarding homework, we attempt to utilize literary modes of apprehension which they can apply to any text they might read.

- They believe science and engineering are about facts. Philosophy, literature and art are about opinion. They are surprised to learn there are better ways and methods to approach complex issues of life, that their opinions can be exposed to be based upon faulty thinking and are thus subject to criticism and evaluation. Application: This perspective is very difficult to overcome. We attempt to address this by underscoring that our goal is not just to know what we think/believe, but why we think/believe what we think/believe. In class discussion, homework and papers, the emphasis is upon demonstrating the sources and reasons behind their conclusions and the necessity of allowing opposing voices challenge these conclusions.

- They understand the intentional complexity of engineering design but have no category for the intentional sophistication and complexity of literary structure, word choice, etc. Application: This is also very difficult to overcome. The only thing that seems to have had any level of success is the continual attention to detail and the significance of these details to arriving at any conclusion.

- They generally do not possess much of a cultural or historical matrix in which texts can be contextualized. "Didn't people think this back then?" is a common statement. "Well, you've got to remember that Sophocles' view of guilt would have been forced on him by the Catholic Church." "He's one of those B.C. guys." Application: In the first semester, we focus almost exclusively on the immediacy of the text and the development of reading skills. We desire to disabuse them of the excuse that they must be an expert to read productively. At the same time, we provide, in the form of brief handouts, relevant historical information. In the second semester, we organize our curriculum around landscapes of the mind which focus upon a particular theme, period, genre, etc., which explores the significance of coherency, intertextuality and context. Attempts at massive remediation via concurrent lectures have not been successful.

- They are insecure about their ability to read and comprehend. Many have not written an essay since their junior year in high school. Application: We are patient and gear our expectations towards participation for its own sake at the beginning of the first semester and slowly engage the question of the quality of the participation as the semester progresses. Having the text be the final arbiter of its own meaning as opposed to the teacher's reading of the text seems to help students dig in. They cannot use the excuse that they are not an expert because the "experts" don't put them in their place. By constantly returning the attention to particular moments in the text, the student learns, at least in this class, that he must utilize his own resources and those of his classmates.

- In comparison to their counterparts in the college of Liberal Arts, they have led a more sheltered life in respect to experiencing tragedy, dating, living with an insecure future after graduation, etc. In other words, they do not seem to have the same intuitive and experiential grasp of literature. Application: This manifests itself in somewhat idealistic pronouncements about the way the world is and how their future 
will look. Aristotle's comment that you can't teach political science to the youth is relevant to the endeavor to teach humanities to engineering students. It's hard to measure the significance of knowing they have a job waiting for them after graduation makes. They, in general, wholeheartedly believe that hard work and getting grades guarantees success in the world.

These are just some of the factors we take into consideration when designing our courses.

\section{The Two Semester Sequence}

The two semesters are organized differently. In the first semester, all the sections have a common curriculum. The texts we are currently using have been chosen with the following considerations in mind: accessibility; genre, geographical, and historical variety; the specific themes of freedom, the human condition, and happiness; length; and "teachability/discussability." Please see the attached list of texts used this past semester. The second semester is organized around what we call "landscapes of the mind." These landscapes are organized around a coherent theme, a historical period, a particular genre, etc. The second semester utilizes only one moderator per class. Each class is composed of two landscapes and teachers switch sections at the halfway point. This past semester, these were the landscapes offered: Love and Friendship, Imperial Russia, The Black Death in Art and Literature, The Bible as Literature, American Literature, The Drama of Desire, Julius Caesar, Futurism and Epic. One of the reasons we moved to a variable curriculum in the second semester was for the moderators. We all desired (needed) the opportunity to teach different texts, be able to experiment and feel a greater sense of ownership.

\section{Conclusion}

"What works and doesn't work?" is a complex question. To answer this question, we had to agree first on what our goals were--on what we thought successful learning looked like.

Teaching students and not texts via a text-based approach centered on discussion is working fairly well at the University of Colorado. We have the advantage of having an endowment which allows a small teacher-student ratio--1:7 (2:14) in our first semester classes, but would attempt to accomplish the same goals under normal funding constraints. We are an elective program and, therefore, do not have to service the entire college. As a result, we get self-selected students who know the reputation and expectations of our model and choose to sign up. We are a junior-senior level program and so our students are a little more mature and have proven their ability to handle the rigors of an engineering curriculum. We think that our overall principles and goals are both effective and productive--i.e. they "work." Many concrete manifestations of these principles "have not worked" or "have worked only partially." As a program, we continue to evaluate and make adjustments and are generally gracious to each other as we risk and fail to teach students. 


\section{Summary of "Texts":}

First Semester:

Douglass: Narrative of the Life of Frederick Douglass

Epictetus: The Enchiridion

Stockdale: Courage Under Fire

Sophocles: Oedipus Rex

Orwell: Politics and the English Language

Montaigne: On the Education of Children

Western Poetry

Trip to the opera: "Spanish Hour" and "Gianni Schicci"

O'Connor: A Good Man is Hard to Find

Trip to Art Museum in which students were required to copy a painting using pastel crayons

Plato: The Apology of Socrates

Aristotle: The Nicomachean Ethics: Books 1-3

Dostoevsky: The Grand Inquisitor

Shakespeare: Hamlet (including having to act out a scene)

Haiku

Conrad: Heart of Darkness

Film: Citizen Kane

\section{Biographical Information}

\section{SCOT DOUGLASS}

Scot Douglass is the coordinator for the Herbst Program of Humanities for Engineers at the University of Colorado, Boulder. He has taught in the Herbst program for three years. He is a $\mathrm{PhD}$ candidate in Comparative Literature, has a ThM from Dallas Seminary and a B.S. in Cellular Biology from the University of Arizona. email: douglass@ucsub.colorado.edu 